\title{
A CIVILIZAÇÃO COMO IDEAL: EDUCAÇÃO NA IMPRENSA DE UBERABINHA-MG NA PRIMEIRA REPÚBLICA
}

\author{
Luciana Araujo Valle de Resende ${ }^{\mathrm{i}}$; \\ Wenceslau Gonçalves Neto ii, \\ Carlos Henrique de Carvalho ${ }^{\text {iii }}$
}

\section{RESUMO:}

O presente estudo, resultante de projeto de pesquisa financiado pelo Conselho Nacional de Desenvolvimento Científico e Tecnológico (CNPq), visa ampliar a compreensão da História da Educação em Minas Gerais, tomando a cidade de Uberabinha como referência no correr da Primeira República. A nossa preocupação foi oferecer uma visão panorâmica em torno das discussões sobre educação que circulavam em Uberabinha, MG (hoje Uberlândia), buscando nos jornais e nas Atas da Câmara Municipal as iniciativas locais no campo educacional e, ancorados nessas fontes, identificar os possíveis objetivos que nortearam a produção do discurso sobre a educação vigente no município à época. As especificidades desse discurso devotado à educação podem ser captadas através da análise de alguns jornais, dentre eles destacam-se Paranayba, O Progresso e A Tribuna. Esta imprensa, de caráter não pedagógico, nos permitiu encontrar um cabedal de informações das mais variadas formas do pensamento educacional, além do papel pioneiro que ela desempenhou enquanto fonte para o estudo da constituição e da dinâmica da questão educacional na cidade. Observou-se que nos periódicos circulavam concepções de cunho liberal e positivista que ganham aceitação entre os estratos sociais mais intelectualizados da cidade, identificados com os princípios republicanos. Portanto, foi na tentativa de identificar como se materializaram essas iniciativas, numa localidade distante dos grandes centros, que buscamos compreender as propostas educacionais que foram publicizadas por meio dos jornais, pois, se de um lado os liberais apresentavam, via imprensa, a República como o espaço da visibilidade, da transparência, da verdade, da ordem e do progresso, por outro, alguns segmento sociais a transformavam numa espécie de tribuna de verdades eternas, que não podiam ser abaladas pelos detratores da ordem estabelecida, que almejavam destruir os valores morais da sociedade brasileira.

Palavras-chave: civismo, educação, ensino público, progresso, religião.

\section{CIVILIZATION AS IDEAL: EDUCATION IN THE UBERABINHA-MG PRESS DURING THE FIRST REPUBLIC}

\begin{abstract}
:
This study, resulting from a research project supported by Conselho Nacional de Desenvolvimento Científico e Tecnológico (CNPq), broadens the knowledge about Education History in Minas Gerais, taking the city of Uberabinha as a landmark during the First Republic. The major concern was to provide an overview around the discussions about education that circulated in Uberabinha, MG (presently Uberlândia), searching the newspapers and Minutes of the Town Council for local enterprises in the education area, and, based on these sources, to identify the possible objectives that guided the formation of the prevailing discourse about education in the city at that time. The specificities of that discourse devoted to education can be captured from the analysis of some newspapers, among which Paranayba, O Progresso and A Tribuna deserve special note. This press, of non pedagogical character, allowed us to find a stock of information from the most varied forms of educational thinking, besides the pioneer role it performed, as a source for the Revista HISTEDBR On-line, Campinas, n.34, p.127-141, jun.2009 - ISSN: 1676-2584 127
\end{abstract}


study of the constitution and dynamics of the education topic in the city. In these periodicals, circulated liberal and positivist conceptions that were accepted by the most intellectual social strata of the city. These strata begin to defend the republican principles. Therefore, we attempted to identify how these initiatives were materialized in a location away from the major population centers, to understand the educational proposals that were published in the newspapers, since from one side the liberals presented, in the press, the Republic as a space for visibility, transparency, truth, order and progress, from the other side, some social segments transformed it into a sort of platform of eternal truths, which could not be shaken by the detractors of the established order, and that coveted destroying the moral values of Brazilian society.

Key-words: civism, education, public teaching, progress, religion.

\section{Introdução}

Com o ocaso do período Imperial, temos o início de uma nova fase, republicana, que foi aguardada e sonhada por muitos como a solução para diversos desafios que se colocavam para o país, inviabilizando o desenvolvimento, o alcance do progresso. Dentre esses, podemos mencionar o atraso econômico, o alto índice de analfabetismo e a limitada participação da população nas decisões políticas. No entanto, pela própria forma como foi implementada, a República será marcada por contradições e indefinições que persistiram durante toda a Primeira República, algumas permanecendo até os dias atuais.

Entretanto, a despeito desses inconvenientes, tem-se como certo que, independente dos interesses dos grupos que disputavam o poder republicano e da maneira como desejavam fazer uso desse poder, a educação aparecia a todos como uma necessidade e precisava ser disponibilizada para o maior número possível de pessoas, tentando superar uma situação em que a população em sua maioria era de analfabetos e o setor educacional recebera precários investimentos do poder público durante o regime anterior.

Segundo Ribeiro (2003, p. 81), os índices de analfabetismo da população brasileira para pessoas de todas as idades nos anos de 1890, 1900 e 1920 evoluíram, respectivamente, em valores percentuais, da seguinte forma: $85 \%, 75 \%$ e $75 \%$.

Tomando esses percentuais como referência, Vieira (2004), utilizando-se de informações extraídas do jornal A Tribuna (Uberabinha, p.1, 22/02/1925) e do censo do IBGE, compõe um interessante quadro comparativo, no qual é possível visualizar o peso dos analfabetos na população total e na de 7 a 14 anos, em 1920, em Uberabinha, Minas Gerais e Brasil.

\begin{tabular}{|l|c|c|c|c|c|c|}
\hline \multicolumn{1}{|c|}{ DESCRIÇÃO } & \multicolumn{2}{|c|}{ UBERABINHA } & \multicolumn{2}{c|}{ MINAS GERAIS } & \multicolumn{2}{c|}{ BRASIL } \\
\hline População total & $24.420^{*}$ & $\%$ & $5.888 .174^{* *}$ & $\%$ & $30.635 .605^{* *}$ & $\%$ \\
\hline População de analfabetos & $14.073^{*}$ & 57,62 & $4.671 .533^{* *}$ & 79,33 & $23.142 .248^{* *}$ & 75,54 \\
\hline $\begin{array}{l}\text { População total de 07 a 14 } \\
\text { anos }\end{array}$ & $4.390^{*}$ & $\%$ & $1.318 .365^{* *}$ & $\%$ & $6.582 .917^{* *}$ & $\%$ \\
\hline $\begin{array}{l}\text { População de analfabetos - } \\
\text { 07 a 14 anos }\end{array}$ & $3.505^{*}$ & 79,84 & $1.112 .073^{* *}$ & 84,35 & $5.282 .886^{* *}$ & 80,25 \\
\hline
\end{tabular}

Fonte: VIEIRA, Flávio César Freitas. Profissionalização docente e legislação educacional: Uberabinha (1892 - 1930). Uberlândia: Programa de Pós-Graduação em Educação da UFU, 2004 (Dissertação de Mestrado). 
Mesmo conhecendo as dificuldades de se realizar um censo no período estudado, devido aos problemas de acesso às comunidades interioranas num país de grandes extensões como o Brasil e com uma população predominantemente rural, podemos considerar esses dados confiáveis, uma vez que são recorrentes em diversas fontes e condizentes uns com os outros, quando analisamos a realidade de uma forma mais totalizante e longitudinal. Por eles, é possível verificar a situação de precariedade da instrução escolar em todas as esferas territoriais, o que se refletia não somente nos números apresentados, mas também na vida e no espírito do cidadão brasileiro e uberabinhense, tanto que esse sentimento foi explicitado numa manifestação da Profa. Antonieta Villela na imprensa local (A Tribuna, 09/04/1922, p.2):

É desolador o numero de analphabetos que conta o nosso paiz. Quantos genios ignorados à sombra do esquecimento, tacteando nas trevas da ignorancia, à procura de uma estrella-guia!? Quantas intelligencias avidas do saber jazem escondidas, abandonadas no mundo da politica cancerosa, qual semente rara em terreno abrupto!? A politica sem patriotismo é o desastre de um povo.

Ainda nessa mesma direção, agora em favor da instrução pública, o jornal $O$ Progresso (24/11/1907, p. 1) trazia o seguinte:

Affirmação, cathegorica, isto que aqui fica dito está nitidamente comprovado pelo modo como é ministrada a instrucção estadoal e municipal em Uberabinha. Funcionando em prédios que não têm o menor requisito para estabelecimento de educação, as nossas escolas publicas resentem-se de tudo.

Falta-lhes mobiliario, hygiene, material, enfim, tudo porque o ensino está completamente desorganizado.

A escola do sexo mascolino foi suspensa por motivos frivolos, sem que o governo procedesse previamente a mais livre syndicancia.

Percebe-se, dessa forma, que o ensino público uberabinhense, assim como o nacional, apesar de ser depositário de expectativas de melhorias individuais e sociais, carecia, por parte da classe dirigente, de uma maior atenção, e entenda-se por esta, investimento financeiro, organização de um sistema de educação e fiscalização. Até nas necessidades mais básicas para a manutenção do sistema de ensino, o município encontrava dificuldades, como observa-se numa sessão ordinária da Câmara, realizada em 1910:

Indicamos que fiquem suprimidos provisoriamente, em virtude do estado precário das finanças do município, os cargos de zelador, das ruas e de professora municipal, vago com a morte da distinta senhora que o occupava ha annos. Uberabinha, 28 de Dezembro de 1910" (Actas da Camara, 28/12/1910, p.2).

Percebe-se, por essa passagem, que os vereadores de Uberabinha não assumiam decididamente como elemento prioritário a educação, nem se preocupavam com a continuidade das condições de ensino da cidade. O que persiste é o descaso com a educação, como se pode observar na ata da sessão ordinária realizada no dia 16 de janeiro de 1911, quando a mesma Câmara torna sem efeito na decisão acima a parte referente ao 
cargo de zelador das ruas, mas mantém a que diz respeito à extinção do cargo de professora municipal.

Percebe-se, então, que as reportagens, veiculadas pelos periódicos locais, bem como a documentação oficial, ajudam-nos a compreender melhor as estatísticas nacionais, como, por exemplo, as enunciadas anteriormente por Ribeiro. E é com intuito de esclarecer e identificar as origens e/ou os destinos das ações públicas, dos dados e das informações em âmbito nacional, que a utilizamos como fonte. Ela nos permite vislumbrar novas interpretações, ou seja, ao nos depararmos com determinadas reportagens voltadas para as questões educacionais, sentimo-nos obrigados a questionar tanto a realidade descrita como o próprio conteúdo exposto, além de estabelecer diversas correlações. Como a educação era pensada? Que preocupações havia sobre o ensino? Quem levantava problemas relacionados à situação educacional do país? Quais saídas eram propostas? Do quê ou de quem dependia colocar em prática esta ou aquela alternativa? As respostas a estas e outras perguntas, encontradas na documentação, desvelaram um outro Brasil, uma outra Minas Gerais, um outro Triangulo Mineiro e uma outra Uberabinha.

São novos sujeitos e novos problemas que, por sua vez, vão compor diferentes caminhos para se entender a História da Educação no Brasil. Trata-se de desnudar experiências e visões diversas, que também não deverão servir simplesmente para compartimentar a história, mas para acrescentar outros elementos à sua compreensão. A educação torna-se tema geral e pode ser tratada no âmbito do local justamente por evidenciar nesse local a presença das peculiaridades dos debates propostos no período, como ainda suas diferenças, suas individualidades, permitindo comparações e interrelações com o contexto nacional.

Desta forma, a investigação feita em espaços micro, como o de Uberabinha, permite-nos entender mais claramente o que se desenrola no espaço macro, como a educação nacional. E o olhar sobre o conjunto da educação nacional passa a ser mais denso, carregado de uma complexidade que inclui o local em todas as suas dimensões. Local e nacional interligam-se de forma definitiva.

Assim, a proposta deste trabalho amplia-se e busca compreender como se materializaram os conceitos, as reflexões, os modos de pensar, os pontos de vista, enfim, a (re)criação das idéias gerais, que circulavam no principal meio de comunicação da cidade de Uberabinha - a imprensa escrita - sobre o ensino, não só pela riqueza das opiniões que expressam, mas também pela discussão das condições da educação local e descrição das instituições educativas de importância para a época ou das que se estabeleceram em períodos mais remotos.

Esse alargamento, tanto em termos de objetos de pesquisa quanto das fontes utilizadas, vem ganhando importância cada vez maior na forma de se fazer história a partir da disseminação dos pressupostos adotados pela Escola dos Annales (Burke, 1997) que, ao substituir a narrativa tradicional dos fatos por uma problematização dos mesmos e ao incorporar no campo da história todas as atividades humanas e não apenas as de caráter político, cria um campo fecundo para o estudo da realidade local, onde se materializam e ganham visibilidade as contradições, as lutas de poder e o vai-e-vem da história. Essa nova forma de compreender a história, não só amplia as fontes documentais, como também os objetos e suas possibilidades de estudo, contribuindo para o desenvolvimento e a compreensão de questões importantes ligadas ao cenário nacional.

Ao elegermos o local como perspectiva de abordagem para a História da Educação no Triângulo Mineiro, mais especificamente na cidade de Uberabinha, estabelecemos um recorte, uma fronteira onde algo começou a se fazer presente: sociabilidades diversas, em 
temporalidades variadas, que passaram a ganhar formas retratadas na busca de outros sentidos.

Dessa forma, podemos considerar que o presente estudo ao enfatizar o ensino público e suas representações em âmbito local também o faz a nível nacional por meio desta região que representa uma amostra significativa da realidade brasileira.

Esse trânsito entre as realidades local e global apresenta importantes desafios e possibilidades no desvelar historiográfico que, longe de se mostrarem como realidades divergentes ou contraditórias, se mostram complementares.

\section{A imprensa como fonte de pesquisa}

Os estudos que utilizam a imprensa como referência para a compreensão da realidade brasileira, nos últimos tempos, têm se desenvolvido muito nos meios acadêmicos, notadamente na área de História.

A conjugação da informação jornalística com a metodologia histórica tem se mostrado produtiva para ambas as áreas. Tanto a imprensa ganhou na forma de tratar suas informações e no enriquecimento de sua própria história, como a história propriamente dita encontrou um novo manancial de dados, a partir do qual pode ampliar seu ângulo de visão e promover interpretações mais abrangentes e que consigam reproduzir de forma mais eficiente a dinâmica social.

Da mesma forma, no campo educacional vêm surgindo importantes trabalhos que tomam como objeto de estudo a imprensa educacional, dando um grande contributo tanto em termos de percepção da realidade como de demonstração metodológica de novas formas de se compreender a educação através da utilização de outras fontes de informação. O universo da imprensa é ricamente diversificado, permitindo múltiplas aproximações, mas têm sido destacadas aquelas que tratam especificamente das publicações voltadas diretamente para as questões educacionais. Este veio tem se mostrado excepcional para o aprofundamento de questões relativas à prática docente, aos métodos e técnicas utilizados nas escolas em épocas distintas, a nuances da organização dos profissionais da educação e, também em momentos mais recentes, retrata em parte os debates em torno da laicização do ensino e da reação de grupos ligados ao pensamento católico. Além disso, esses periódicos esboçam, principalmente, o trabalho docente e vão além da interpretação da lei, da crítica ou defesa de políticas governamentais, da presença ou omissão do Estado.

$\mathrm{Na}$ inter-relação desses dois campos de conhecimento, não apenas se promove um arejamento na pesquisa histórico-educacional, com saudáveis consequiências para a área, como também se projeta a imprensa como um campo extremamente promissor para este fim. Contudo, por ser a imprensa um campo marcado pela variedade, a aproximação pela via das publicações especializadas é apenas uma das possibilidades, mas não a única, ainda que talvez a mais prestigiosa. Expõe-se, portanto, a importância de se utilizar outras manifestações da imprensa escrita, notadamente a que chamamos de periódica, para a análise histórica da educação. E esta se mostra extremamente fecunda para a compreensão das representações, dos embates, das aspirações e frustrações de uma sociedade que se pauta pela crença no progresso e na viabilidade da educação para promovê-lo.

É com este pressuposto que examinaremos a imprensa local, privilegiando os jornais "O Progresso", "Paranayba" e "A Tribuna", pelo relevante papel desempenhado para a compreensão dos debates educacionais, ao apresentar os fundamentos precípuos que deveriam gerir o plano educativo, mas não menos importante discorreram também a respeito dos princípios filosóficos da educação. 


\section{Uberabinha na senda do civismo, progresso e religião}

Analisando esses periódicos, pode-se perceber a ênfase dada às questões relativas ao civismo/patriotismo, educação, progresso e religião, até porque, estas representam as diversas facetas de um único e abrangente objetivo que é o desenvolvimento do país, no momento em que este necessitava se consolidar como República. Dessa forma, essas categorias serão, a partir de agora, discutidas, buscando-se estabelecer em que medida elas se influenciavam mutuamente e de que forma as realidades nacional e local se interrelacionavam.

Como já foi mencionado no início deste estudo, com a Proclamação da República, em 1889, o rompimento com os símbolos e valores do Império, a separação entre Estado e Igreja, etc., fazia-se necessário o estabelecimento de uma "nova" identidade nacional que garantisse a unidade da incipiente República. O caminho que se imaginou para alcançar semelhante propósito foi o da educação, que incutiria no povo não apenas os ideais de civismo mas também conformaria o perfil do "cidadão republicano".

O povo, excluído de longa data do processo de transformação política, precisava de elementos de afirmação, reais ou simbólicos, que o aproximassem ou o identificassem com os princípios republicanos. Era, então, segundo Carvalho (1998, p. 32), necessário criar um sentimento de pertença, de identidade e de unidade dessa população aos novos pressupostos políticos e sociais:

No Brasil do início da República, inexistia tal sentimento [de comunidade, de identidade coletiva]. Havia, sem dúvida, alguns elementos que fazem parte de uma identidade nacional, como a unidade da língua, da religião e mesmo a unidade política. (...) A busca de uma identidade coletiva para o país, de uma base para a construção da nação, seria tarefa que iria perseguir a geração intelectual da Primeira República (1889-1930).

A possibilidade de se conseguir esse objetivo de uma forma mais rápida e eficaz foi vislumbrada por meio da educação, que tinha na escola a sua forma de materialização. E a escola uberabinhense, conforme podemos verificar na reportagem abaixo, não ficou alheia a esse movimento, tornando-se um instrumento de formação e cultivo do civismo em meio à classe estudantil.

O cultivo do civismo nestes ultimos annos, fazendo compreender à mocidade os deveres e as obrigações dos cidadãos para com a patria tem feito muita luz sobre assumptos que outrora só criou conhecidos pelos homens de cultura intellectual.

Assim, as noções mais simples sobre a Patria, a Republica, a Bandeira, o Estado, etc, são carinhosamente expostos pelos professores, nos institutos de ensino primario.

A Bandeira foi idealizada por cultores do positivismo; por isso nella figura esse lemma, que é fundamental na politica positivista e que procuraremos esclarecer emprestando-lhe o seu tudo verdadeiro, conforme os theoricos positivistas.

Aristoteles, o grande philosopho da antiguidade, havia tido a comprehensão nitida da estatica social e, portanto, da ordem.

Comte, fundador da philosophia positivista, harmonizou esta idéa da ordem com a do progresso, creando assim a dynamica social.

O primeiro esta dara condições de equilibrio da organização social, em repouso pôde conceber o equilibrio social no estado de movimento.

Revista HISTEDBR On-line, Campinas, n.34, p.127-141, jun.2009 - ISSN: 1676-2584 132 
A cultura tem como objeto a sabedoria; como, porém, a base da felicidade está na pratica da virtude toda sabedoria se deve pôr ao serviço do Bem, porque, de outra maneira, seria encaminhar a humanidade para a perdição. A ordem está nisso. Essa subordinação de nossos actos preceitos da sciencia, da moral e da Justiça, regulando o grão de liberdade de cada um é a própria ordem. Ella é a base necessaria de toda organização.

A ordem tem seu fundamento no caracter objetivo da invariabilidade das leis naturaes. A ordem artificial, desprezado ponto de vista subjectivo, repousa necessariamente sobre a ordem natural e resulta do conjucto das leis reaes. A correlação que se nota entre a existencia e o movimento, transportada para o campo social, se manifesta egualmente entre a ordem e o progresso. A ordem se torna, assim, a condição permanente do progresso, do passo que este constitue sempre o obejectivo daquella. Enfim, não se comprehende o progresso, sinão em uma sociedade em que a ordem assume, a cada passo um estado de maior perfeição.

E o progresso deve ser visto como um aperfeiçoamento, na evolução da ordem. A legenda convem muito à bandeira de uma nação como a brazileira, em que a democracia que resalta de toda a organização política, offerecendo a todos os cidadãos a mais ampla liberdade, lhes garante também o direito de acalentar as maiores aspirações. Ella exprime tambem a conciliação dos programas de dois partidos que sempre existiram na política: os conservadores, que teem na ordem o seu principal argumento e os progressistas, já chamados liberais, já democraticos, que veem todos as suas esperanças no progresso. Nem a ordem immovel, nem o progresso que não se funda na ordem são bastantes fecundos; pelo contrario, o mais completo ideal se encontra na ordem que envolve e assim progride. Ahi os dois ideais se harmonizam numa formula unica ordem e progresso (A Tribuna, 10/04/1921, p.1).

Além da importância dada à escola na formação desse sentimento cívico na mocidade, camada da população que representava, no imaginário local e nacional, o futuro da nação, outros aspectos interessantes estão presentes nesta reportagem, como as idéias de ordem e progresso, nas quais a primeira é vista como condição necessária para a segunda, e a utilização da Bandeira Nacional como instrumento de representação da nacionalidade.

Em relação à utilização dos símbolos nacionais como um dos elementos constituidores dessa identidade republicana, Carvalho (1998, p. 10-11) discute a importância dos mesmos na formação do imaginário social, que, por sua vez, desempenha um papel essencial na legitimação de qualquer regime político:

A elaboração de um imaginário é parte integrante da legitimação de qualquer regime político. É por meio do imaginário que se podem atingir não só a cabeça mas, de modo especial, o coração, isto é, as aspirações, os medos e as esperanças de um povo. É nele que as sociedades definem suas identidades e objetivos, definem seus inimigos, organizam seu passado, presente e futuro. O imaginário social é constituído e se expressa por ideologias e utopias, símbolos, alegorias, rituais e mitos. Símbolos e mitos podem, por seu caráter difuso, por sua leitura menos codificada, tornar-se elementos poderosos de projeção de interesses, aspirações e medos coletivos. Na medida em que tenham êxito em atingir o imaginário, podem também plasmar visões de mundo e modelar condutas. 
A manipulação do imaginário social é importante principalmente nos momentos de mudança social e política, em momentos de redefinição de identidades coletivas.

Aliadas à questão do civismo, encontramos as idéias de ordem e progresso. Estampadas na nossa bandeira, essas referências de cunho positivista, refletem a necessidade de se formatar a sociedade brasileira, de conformá-la aos novos ideais, para que assim, de uma forma ordeira e civilizada, se consiga, num contínuo de desenvolvimento, trilhar os caminhos do progresso, já alcançado por outras nações que se dedicaram à instrução intelectual de sua população. Imbuídos do pensamento de que a escola representa um desses caminhos que levam ao progresso, também em Uberabinha a instrução é conclamada a dar a sua contribuição:

A instrucção é a força que alimenta e desenvolve a intelligencia. É a luz que guia o cerebro. É a eletrecidade potente que move a massa dos seculos. É o alicerce indispensável à vida e à integridade do homem, sem o qual todo o seu esforço seria improficuo.

(...)

A instrucção - esta alavanca que descobre thesouros e dimana a luz, deveria ser implantada no seio de uma nação com o mesmo caracter sagrado, tal como é a religião para todos os povos (A Tribuna, 09/04/1922, p.1).

E mais do que contribuidora, a escola é tida como o caminho que leva ao desenvolvimento pessoal, e deste ao social, cujo sucesso depende basicamente do interesse e do esforço de cada um:

Optimo symptoma de desenvolvimento, o amor que vae notando ultimamente nesta cidade pelas cousas referentes á instrucção é uma prova evidente e, por isso mesmo, mais do que flagrante, de que estamos caminhando francamente para a senda luminosa do progresso.

Sendo um dom humano, perfeitamente accessivel a todos os individuos dotados de boa vontade e de perseverança, a instrucção nada mais é do que a manifestação da cultura de um povo e o signo que caracterisa a passagem deste mesmo povo pela Historia.

O homem, para dilatar os seus horizontes e para vencer galhardamente no embate da vida hodierna, precisa armar-se de uma certa dose de conhecimentos indispensáveis e que lhe só poderá adquirir instruindo-se solidamente.

Parece anachronico querermos fazer a apologia do ensino na hora actual, mas confessando toda a verdade, certifiquemo-nos de que a sua propaganda é urgente, porque o ser humano só se torna apto para a vida pelo desenvolvimento do espírito, pelo gráo de actividade que a sua intelligencia puder expargir.

Lembremo-nos por isso, de que as nações mais adiantadas do mundo são justamente aquellas em que a instrucção popular está mais diffundida, aquellas em que as escolas contam em maior número.

E, considerando deste modo, encaremos seriamente a nossa situação perante os paizes adiantados, miremo-nos nos exemplos que elles nos dão todos os dias, convençamo-nos de que ainda não temos nada feito neste sentido e desponhamo-nos a empenhar o melhor do nosso esforço 
trabalhando pela educação popular, que o grande Clemenceau diz ser a principio fundamental de toda politica republicana.

(...)

E ja que a escola publica deixou de ser o santuário sagrado onde deveria arder incessantemente a pyra do amor pátrio, voltemos as nossas vistas para o ensino particular, que será o unico capaz de formar o espirito e o coração da formosa mocidade uberabinhense (O Progresso, 24/11/1907, p. 1).

Aqui nos é apresentada a quarta e última categoria de análise abordada por este estudo: a religião. Esta se faz presente no seio da sociedade de várias formas. A primeira delas refere-se à sua doutrina e crença que se encontram arraigadas na mente e espírito do povo brasileiro, que não perde a sua fé e que não deixa de cultivar seus valores espirituais pelo fato de o Estado, agora republicano, declarar-se laico.

Esse caráter religioso da população brasileira e uberabinhense pode ser confirmado por meio da imprensa local, que é um dos veículos de expressão da sua religiosidade. A reportagem abaixo, apesar de longa, é importante para a compreensão de como a religião estava enraizada na forma de ser e de pensar da população, bem como de algumas pessoas que compunham o quadro dirigente do Estado e, por extensão, do país. Trata-se do discurso com que Honório Guimarães, professor público de Uberabinha e então secretário e membro da Comissão de Bases do Congresso do Professores, reunido pela segunda vez em Belo Horizonte em dezembro de 1910, refutava os argumentos do congressista José Polycarpo de Figueiredo, sobre o ensino religioso nos escolas. Nela, Honório Guimarães compara o mestre ao sacerdote, cuja influência ultrapassa os limites da escola e permeia todas as ações do aluno, uma vez que o primeiro é tido como um exemplo a ser seguido, uma figura respeitável e idônea, devendo, assim, manter uma postura reta e austera. Com esses argumentos, pronuncia-se contrário à indicação de um congressista de Conceição do Serro, por julgar que este tenha infringido tais regras de conduta e de moral:

(...) $\mathrm{O}$ sacerdote deve ser ministro de Christo, as suas funções são as do proprio Enviado, o mestre e sacerdote, tem funcções extensas sobre os alumnos, na escola, na rua e em casa. O que o mestre fizer sempre o fará no caracter de mestre. Na casa do alumno mesmo elle tem dever de corrijir e ensinar. Tal será a confiança que, pelo seu procedimento explendido, pela moralidade immaculada, pelo exato cumprimento dos seus deveres, pela dedicação e interesse demonstrado pelos seus educandos, imporá a sua norma de conducta julgada irrepreensível: e o mestre fica sendo, para o pae de familia, o irmão mais velho, digo successor do chefe da casa. Pode reprehender e ensinar no caracter de pae, diante dos proprios paes. (La na minha localidade a conducta da familia unanime que me prestigia, felizmente, é assim). Eis pois como o professor tem a sua funcção. (...) $\mathrm{O}$ professor, portanto, nunca deve abusar de seu prestigio, para impor mas doutrinas, ou dogmas quaesquer, de encontro á lei geral que deve ser obedecida. Outro argumento: Que se dirá de um professor que ande, pelas ruas e praças de sua localidade, ás deshoras, tardes momentos de noite morta, violão aos braços, dedilhando versos á pallida visão dos seus amores ? - Que este professor não o é, na significação do termo proprio; se o fosse guardaria a compostura das suas funcções. E o mesmo dir-se-a de um rapaz que seja, por exemplo um collector? Não. Mais feliz do que nós, elle pode cantar ao violão e 


\begin{abstract}
deleitar-se nas serenatas, porque não tem prolongada consigo, a representação official, que temos nós outros. Portanto, si o professor tem, acompanhando-o, a representação de seu cargo, em qualquer parte e em qualquer ocasião; se elle ensinar religião, o faz officialmente, porque, quando não o seja, pode-se presumir, que, só devido á sua forca moral sobre os meninos, elle consegue trazellos ao ensino da doutrina. Isto seria, peço permissão para dizel-o, a prevaricação moral do professor, o abuso de confiança no cargo que exerce. (...) Ora, se a tolerancia em geral, é a melhor virtude de um cidadão; e si nós, professores, devemos ser o modêlo perfeito do bom cidadão; si aos meninos devemos ensinar a tolerância religiosa - porque nós proprios não obedecermol-a? Aqui, nesta casa de Congresso, é a concentração das boas normas. A tolerancia religiosa é uma boa norma de conducta. Infringiu-a o nobre congressista de C. do Serro, quando, hontem, do alto da tribuna, que dignamente occupava, referiu-se com mófa aos livres-pensadores. Não o sou, tenho minhas ideias que mesmo na maior intimidade procuro occultar. Sirvo a um principio na firmeza dos meus ideaes e na paz da minha consciencia" (O Progresso, 28/01/1911, p. 01-02).
\end{abstract}

A segunda maneira da religião se fazer presente é por meio das escolas confessionais, que assumem um papel fundamental na educação brasileira, uma vez que o setor público mostra-se incapaz de atender e satisfazer as necessidades de escolarização da população. Mesmo cientes da importância da educação, a sociedade, tanto uberabinhense quanto brasileira, encontra-se carente desse tipo de formação: a população é predominantemente rural, o analfabetismo, como vimos anteriormente, atinge percentuais altíssimos e o número de escolas é insuficiente para atender a crescente demanda pela instrução escolar.

Permanece, assim, o espaço, que fora aberto desde o período colonial, para a atuação das instituições religiosas na formação de mentalidades e no direcionamento das ações da população em diferentes níveis e camadas sociais:

(...) Meninas de sete annos de idade até aos oito, mais ou menos, fazerem crochets, bordados, crivos, camisas para homens, fexús e cachinets; e alem disso lerem e escreverem desembaraçadamente como se fossem já diplomadas. Aconselho aos pais de família que tiverem filhas e que queiram educal-as, não mandarem em outro collegio a não ser o das irmãs de caridade, porque lá é que se vê e pode-se observar o capricho e o cuidado que ellas tem para com as dicipulas, lecionando-as tudo que for de utilidade e sciencia.

E portanto estão dando provas que muito trabalharam e estão trabalhando para progredir a instrucção nesta localidade (O Progresso, 17/11/1907, p. $3)$.

Embora a Constituição republicana declarasse a laicidade da nação e da escola brasileira, a Igreja católica, além das instituições confessionais que mantinha e pelas quais continuava próxima aos corações e mentes da população, insistia também na abertura de uma inserção nos estabelecimentos escolares públicos por meio do Ensino Religioso, como verificado pela divulgação do telegrama abaixo:

Telegrammas

Ensino Religioso nas Escolas 
Bello Horisonte, 23 - Os srs. Bernardo Monteiro, Bueno Brandão e conego Rollin já apresentaram mais de 200 listas de localidades do Estado pedindo á camara dos deputados o ensino religioso (Paranayba, 24/09/1914, p.3).

Essa problemática é também trazida por Peixoto (1983, p. 59), ao analisar a política mineira nos anos vinte e os interesses sociais, econômicos e educacionais relacionados a ela:

O ensino religioso havia sido retirado do currículo das escolas públicas do Estado em 1906, pelo Presidente João Pinheiro, que via neste ato um símbolo da independência do poder público em relação à Igreja, um símbolo da implantação do Estado leigo. Em 1928, Antônio Carlos, atendendo às reivindicações do grupo católico, reintroduz a religião no currículo das escolas mineiras e, com esta medida, conquista a adesão do grupo católico para as medidas de caráter liberal de seu governo.

\section{Educação: "caminho para o desenvolvimento"}

Pelo que foi exposto até o momento, podemos perceber a importância dada à educação escolar como uma das formas, se não a principal, para se obter o desenvolvimento e o progresso tão almejados pela sociedade. Essa crença na educação foi destacada por Nagle (2001, p. 135-136) ao analisar os movimentos chamados de entusiasmo pela educação e otimismo pedagógico:

O entusiasmo pela educação e o otimismo pedagógico, que tão bem caracterizam a década de 1920, começaram por ser, no decênio anterior, uma atitude que se desenvolveu nas correntes de idéias e movimentos político-sociais e que consistia em atribuir importância cada vez maior ao tema da instrução, nos seus diversos níveis e tipos. É essa inclusão sistemática dos assuntos educacionais nos programas de diferentes organizações que dará origem àquilo que, na década de 1920, foi sendo denominado de entusiasmo pela educação e otimismo pedagógico. (...) Ao atribuírem importância ao processo de escolarização, prepararam o terreno para que determinados intelectuais e "educadores" principalmente os "educadores profissionais" que aparecem nos anos de 1920 - transformassem um programa mais amplo de ação social num restrito programa de formação, no qual a escolarização era concebida como a mais eficaz alavanca da história brasileira.

A sociedade brasileira tem, então, um grande desafio a enfrentar: estrutura educacional, social, política e econômica extremamente precária, com alto índice de analfabetismo, reduzido número de instituições escolares e de professores preparados para ministrar o ensino, o que inviabilizava a concretização da crença de que pela educação o país conseguiria sair da situação de subdesenvolvimento em que se encontrava e equipararse aos países mais desenvolvidos.

Herdeira de um sistema de ensino caracterizado pelas Escolas de Primeiras Letras, a República, tomando como uma das bandeiras de luta a educação popular, propõe uma série de reformas voltadas à estruturação da instrução pública. Uma dessas ocorreu em 1893, no Estado de São Paulo, por meio da qual foram criados os Grupos Escolares que, gradativamente, vão se proliferando por todo o país. 
A respeito dessa nova forma de se organizar o ensino público, Souza (2006, p. 35) diz que: "Ao implantá-lo [modelo de organização do ensino elementar - grupo escolar], políticos, intelectuais e educadores paulistas almejavam modernizar a educação e elevar o país ao patamar dos países mais desenvolvidos". E o caracteriza como "escola primária graduada, compreendendo a classificação homogênea dos alunos, várias salas de aula e vários professores".

Essa iniciativa paulista chegou a Minas Gerais em 1906, por meio da reforma João Pinheiro, e a notícia da mesma e da criação de grupos pelo espaço mineiro será debatida nos anos seguintes em Uberabinha. Em 1908 encontramos manifestação do grande entusiasmo e esperança de melhoria tanto individual quanto social que essa forma de organização escolar despertava na elite local:

Levanta-se no nosso meio a grande idéa do agrupamento das escolas locaes. Os grupos escolares consoantes com o regulamento da instrucção, organisado pelo illustre secretario do interior Dr. Carvalho Britto, estão destinados a produzir resultados compensadores de todos os sacrificios que se possam fazer com a sua installação. O estado de S. Paulo, que em materia de ensino leva a palma a todos os outros da união, ha muito adoptou os grupos escolares em substituição ás escolas isoladas e diariamente novos edificios se levantam destinados à creação de novos grupos, o que prova o bom resultado que se tem colhido nestes estabelecimentos de ensino. Em Uberabinha onde existem para mais de quatrocentas creanças em idade escolar, é justo que se procure dar ao ensino a maior latitude possível, empregando o meio mais proveitoso, menos despendioso e que mais probabilidades de exito offereça. Ora, está provado pelos bons resultados calhidos pelo estado de S. Paulo, que os grupos escolares, prehenchem todas as condições, acrescendo ainda a maior facilidade de fiscalisação por parte do governo. O magisterio primario que por tantos annos, tão descurado foi no nosso estado, encontrou agora no Dr. Carvalho Britto, um fervoroso defensor, que de animo resoluto e inquebrantável tenacidade, vai operando a sua reforma e levando a todos os recantos deste abençoado torrão, a sagrada luz da instrucção, verdadeiro pão do espírito, donde dimanará mais tarde a felicidade do povo mineiro. O Dr. Carvalho Britto, quando outros actos de sua proveitosa administrção na pasta do interior, o não recomendassem à gratidão dos mineiros, seria bastante a reforma no importante ramo da instrucção publica primaria e a sua organisação nos moldes em que não sendo talhada, para recommendal-o à gratidão dos reindouros, coberto das benções de milhares de creanças que lhe deverão não serem contadas ainda no numero dos analphabetos. É preciso que o governo municipal de Uberabinha, unindo-se ao governo do estado, procure trazer para esta cidade, este grandioso melhoramento, que virá dar ao nosso desenvolvimento material, um impulso intellectual e civilisador, de maneira a preparar pelo ensino, os homens do futuro, tornandoos aptos a contribuir pelo seu saber e valor civico, para a felicidade da grande colectividade brazileira. Promova-se a creação de um grupo escolar nesta cidade e ter-se-á prestado ao municipio um dos mais importantes benefícios de palpitante 
necessidade(O Progresso,19/10/1908, p. 01).

A mobilização pela incorporação dessa novidade em Uberabinha não se limitou aos representantes especificamente da educação, mas atingiu também os políticos, redundando na doação de um terreno para que a construção de um grupo escolar fosse concretizada. Esta discussão culminará em proposta apresentada na Câmara Municipal em 15 de maio de 1911, conforme o trecho da ata a seguir e recebeu menção em várias sessões subseqüentes:

Pelo vereador Rodrigues da Cunha foi apresentado a seguinte indicação, que foi dada para ordem do dia de amanhã "indicamos que a Câmara Municipal officie ao Governo do Estado offerecendo os terrenos situados no local antigo Cemitério, no prolongamento da rua Tiradentes e partes adjacentes, nos fundos, para construção de um edifício destinado ao Grupo Escolar. (Actas da Camara, 15/05/1911, p.18).

Os grupos escolares representaram uma fase importante na socialização da educação escolar e na possibilidade de acesso à mesma por parte das camadas populares, uma vez que sua estrutura permitia o atendimento de um número maior de alunos. Essa proposta concebia a escola como um espaço único, no qual funcionariam várias salas de aulas, cada qual com um professor e alunos com características homogêneas, como idade e nível de conhecimento. Representou, também, uma preocupação com a racionalização dos programas de ensino e do tempo, que passa a ser dividido em cursos com duração específica e, dentro desses, as séries, que se relacionavam com as idades dos alunos.

Contraditoriamente, a mesma iniciativa que viabilizou a massificação do ensino, trouxe, também, questões para as quais se buscam soluções até os dias de hoje, que são: a reprovação e junto desta as formas e critérios de avaliação; a classificação dos alunos buscando ou não uma maior homogeneidade das turmas; uma proposta única para a turma, o que normalmente favorece os que têm melhores condições de aprendizagem enquanto os demais são marginalizados do processo; e a (in)disciplina.

Ainda segundo Souza (2006, p. 59),

Em 1893, a criação dos grupos escolares no estado de São Paulo fechou o ciclo de transformações no ensino primário. A forma escolar destinada à grande obra de difusão da escolarização em massa consolidou a estrutura da escola graduada na educação brasileira cujos vestígios permanecem até o presente.

Como se observa pelo fragmento acima, o ideal dos grupos escolares marcou a virada do século XIX para o século XX no Estado de São Paulo. Mas a percepção da importância dos grupos escolares transborda para outras regiões do país aportando, inclusive, na então Uberabinha, o que pode ser verificado tanto pela imprensa local quanto pelas Atas da Câmara, demonstrando a ânsia da pequena cidade pelo alcance do progresso que se seguiria à disseminação dessas escolas.

\section{Considerações finais}

Por meio dos estudos realizados até o momento, verifica-se que a educação sempre foi tema de debates e fonte de controvérsias. Isso porque a sua importância na constituição e desenvolvimento de uma sociedade é algo considerado como inquestionável. Os argumentos a seu favor vão desde as necessidades mais prementes e específicas, como, por Revista HISTEDBR On-line, Campinas, n.34, p.127-141, jun.2009 - ISSN: 1676-2584 139 
exemplo, a de se formar profissionais qualificados para atender à demanda do mercado de trabalho, até às posições mais amplas e de longo prazo, como a de desenvolver a criticidade e a capacidade reflexiva dos cidadãos, para que estes possam ter, na vida da sociedade, uma participação mais decisiva.

Dessa forma, o que era de se esperar é que a escola, sendo um lugar de promoção e disseminação dessa educação, fosse igualmente valorizada e reconhecida por todos os segmentos sociais, políticos e econômicos. E mais, sendo uma produtora e transmissora dos conhecimentos produzidos pela humanidade ao longo de toda a sua história, ela seria portadora de um bem público, garantindo o acesso de todos a esses conhecimentos. Faz-se necessário, então, que não apenas a escola seja valorizada, mas a escola pública em particular, para que todos, indistintamente, possam aceder ao que nela é produzido e debatido.

Contrariamente a essa opinião, o que pudemos perceber, no período estudado, foi uma escola relegada a um segundo plano, com número de estabelecimentos insuficiente para atender à demanda da sociedade, professores nem sempre qualificados mas habitualmente mal remunerados, sem fiscalização e amparo financeiro dos órgãos estatais responsáveis por essas funções. Em suma, a escola apresentava-se com condições mínimas para o seu funcionamento e para o provimento de um ensino que abarcasse tanto a quantidade quanto a qualidade necessárias para atender à demanda daquele momento.

Além do mais, os artigos publicados pelos jornais são a expressão de um difícil equilíbrio entre a força da tradição, que transforma toda ação educacional em uma secular obra de apostolado, e a viabilidade do moderno, no caso a República, concebida como elemento mobilizador de novas potencialidades no campo educacional.

Estas e outras características, apresentadas acima, demonstram os desafios e as possibilidades que se apresentam para os historiadores da educação de articularem os recortes locais com os aspectos mais globais da história da educação, na tentativa de se estabelecer uma interlocução, entre esses dois espaços, que seja capaz de ampliar os conhecimentos produzidos no âmbito da história da educação. Tudo isso nos anima a continuar seguindo por essa caminhada epistemológica, buscando análises complementares que nos permitam compreender com maior clareza o processo de desenvolvimento da educação pública no Brasil, num contexto nacional, mas sem perder de horizonte a compreensão que se inicia a partir do local, no caso em estudo da cidade de Uberabinha. Portanto, o global e local se apresentam muito mais como perspectivas teóricas e metodológicas desafiadoras para os historiadores e não como categorias de análises que inviabilizam estudos que se direcionam para os espaços micro (local) em oposição aos macros (global) na esfera da História da Educação brasileira.

\section{Referências}

BURKE, Peter. A Escola dos Annales (1929-1989): a Revolução Francesa da historiografia. São Paulo: Fundação Editora da UNESP, 1997.

CAMARA Municipal de S. Pedro de Uberabinha. Actas da Camara. Uberabinha, Livro 10, 1910-1911 (Arquivo Público Municipal de Uberlândia-MG).

CAMPOS, Juca dos. Ordem e Progresso. A Tribuna, Uberabinha, MG, ${ }^{\circ}$ 83, p. 1, 10/04/1921.

CARVALHO, José Murilo de. A Formação das Almas - O imaginário da República no Brasil. São Paulo: Companhia das Letras, 1998.

Revista HISTEDBR On-line, Campinas, n.34, p.127-141, jun.2009 - ISSN: 1676-2584 
GRUPO Escolar. O Progresso. Uberabinha, MG, nº 57, p. 1, 19/10/1908.

GUIMARÃES, Honorio. Discurso com que Honorio Guimarães, secretario e membro da Commissao de Bases do Congresso do Professores, reunido pela segunda vez em Bello Horizonte, refutava os argumentos do congressista José Polycarpo de Figueiredo, sobre o ensino religioso nos escolas. O Progresso, Uberabinha, MG, $\mathrm{n}^{\circ}$ 172, p.1-2, 28/01/1911.

NAGLE, Jorge. Educação e sociedade na Primeira República. Rio de Janeiro: DP\&A Editora. 2001.

Paranayba. Uberabinha, MG, $\mathrm{n}^{\circ}$ 2, p.1, 24/09/1914.

PEIXOTO, Anamaria C. Educação no Brasil anos vinte. São Paulo, Edições Loyola, 1983.

PELA Instrucção. O Progresso. Uberabinha, MG, nº10, p. 1, 24/11/1907.

RIBEIRO, Maria Luisa Santos. História da educação brasileira: a organização escolar. Campinas, SP: Autores Associados, 2003.

SOUZA, Rosa Fátima de. Espaço da educação e da civilização: origens dos grupos escolares no Brasil. In: SAVIANI, Dermeval et al. O legado educacional do século XIX. Campinas, SP: Autores Associados, 2006.

TRINDADE, João B. Nota. O Progresso. Uberabinha, MG, no 9, p. 3, 17/11/1907.

VIEIRA, Flávio César Freitas. Profissionalização docente e legislação educacional: Uberabinha (1892 - 1930). Uberlândia: Programa de Pós-Graduação em Educação da UFU, 2004 (Dissertação de Mestrado).

VILLELA, Antonieta. A Instrução. A Tribuna, Uberabinha, MG, nº 134, p. 2, 09/04/1922.

\footnotetext{
${ }^{\text {i }}$ Pedagoga, aluna do Programa de Pós-Graduação em Educação da Universidade Federal de Uberlândia. Email: luciana.resende@netsite.com.br

ii Doutor em História pela USP, professor do Instituto de História e dos Programas de Pós-Graduação em História e em Educação da Universidade Federal de Uberlândia. Email: wenceslau@ufu.br

iii Doutor em História pela USP, professor da Faculdade de Educação e do Programa de Pós-Graduação em Educação da Universidade Federal de Uberlândia. Email: carloshcarvalho06@ yahoo.com.br.
}

Artigo recebido em: 31/05/09

Aprovado para publicação em:31/08/09 